\title{
Estimating surface fluxes over middle and upper streams of the Heihe River Basin with ASTER imagery
}

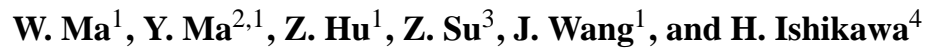 \\ ${ }^{1}$ Key laboratory of land surface process and climate change in cold and arid regions, Cold and Arid Regions Environmental \\ and Engineering Research Institute, Chinese Academy of Sciences, Lanzhou, Gansu, 730000, China \\ ${ }^{2}$ Laboratory of Tibetan Environment Changes and Land Surface Processes, Institute of Tibetan Plateau Research, \\ Chinese Academy of Sciences, Beijing, China \\ ${ }^{3}$ Faculty of Geo-Information Science and Earth Observation, University of Twente, Enschede, The Netherlands \\ ${ }^{4}$ Disaster Prevention Research Institute, Kyoto University, Kyoto, Japan
}

Received: 9 June 2009 - Published in Hydrol. Earth Syst. Sci. Discuss.: 29 June 2009

Revised: 24 April 2011 - Accepted: 2 May 2011 - Published: 6 May 2011

\begin{abstract}
Land surface heat fluxes are essential measures of the strengths of land-atmosphere interactions involving energy, heat and water. Correct parameterization of these fluxes in climate models is critical. Despite their importance, stateof-the-art observation techniques cannot provide representative areal averages of these fluxes comparable to the model grid. Alternative methods of estimation are thus required. These alternative approaches use (satellite) observables of the land surface conditions. In this study, the Surface Energy Balance System (SEBS) algorithm was evaluated in a cold and arid environment, using land surface parameters derived from Advanced Spaceborne Thermal Emission and Reflection Radiometer (ASTER) data. Field observations and estimates from SEBS were compared in terms of net radiation flux $\left(R_{\mathrm{n}}\right)$, soil heat flux $\left(G_{0}\right)$, sensible heat flux $(H)$ and latent heat flux $(\lambda E)$ over a heterogeneous land surface. As a case study, this methodology was applied to the experimental area of the Watershed Allied Telemetry Experimental Research (WATER) project, located on the mid-to-upstream sections of the Heihe River in northwest China. ASTER data acquired between 3 May and 4 June 2008, under clearsky conditions were used to determine the surface fluxes. Ground-based measurements of land surface heat fluxes were compared with values derived from the ASTER data. The results show that the derived surface variables and the land surface heat fluxes furnished by SEBS in different months over the study area are in good agreement with the observed
\end{abstract}

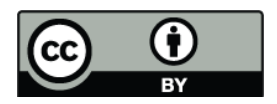

Correspondence to: $\mathrm{W} . \mathrm{Ma}$ (wqma@lzb.ac.cn) land surface status under the limited cases (some cases looks poor results). So SEBS can be used to estimate turbulent heat fluxes with acceptable accuracy in areas where there is partial vegetation cover in exceptive conditions. It is very important to perform calculations using ground-based observational data for parameterization in SEBS in the future. Nevertheless, the remote-sensing results can provide improved explanations of land surface fluxes over varying land coverage at greater spatial scales.

\section{Introduction}

A number of land surface process experiments are currently being performed around the world (e.g., Su et al., 2010), but arid and cold regions have received relatively little attention. To understand hydrological and ecological processes at different scales, the land surface fluxes (and estimates thereof) need to be quantified correctly by using a combination of remote sensing and in situ observations in cold and arid regions. WATER was a simultaneous airborne, satellite-borne, and ground-based remote-sensing experiment conducted in the Heihe Basin, the second largest inland river basin in the northwest arid regions of China. The objective of the WATER experiment was to investigate the water cycle, ecological hydrology and other land surface processes at the catchment scale. At this scale in the study, surface meteorological observation plays a very important role. These observations provide strong information for validation of the remotesensing results (Li et al., 2009). 
Table 1. Ground measurement items in the WATER area.

\begin{tabular}{|c|c|c|c|}
\hline Name & Location & Items & Land surface character \\
\hline Yingke & $\begin{array}{l}100^{\circ} 25^{\prime} \mathrm{E} \\
38^{\circ} 51^{\prime} \mathrm{N} \\
1519 \mathrm{~m}\end{array}$ & $\begin{array}{l}\text { Wind speed, air temperature and humidity }(3 \text { and } 10 \mathrm{~m}) \text {, wind direction, air pressure } \\
\text { precipitation, four components of radiation, and land surface temperature (LST). Soil: } \\
\text { temperature and moisture profile }(10,20,40,80,120 \text {, and } 160 \mathrm{~cm}) \text { and heat flux }(5 \text { and } \\
15 \mathrm{~cm}) . \text { EC }(2.81 \mathrm{~m}) .\end{array}$ & Cropland(maize) \\
\hline Huazhaizi & $\begin{array}{l}100^{\circ} 19^{\prime} \mathrm{E} \\
38^{\circ} 46^{\prime} \mathrm{N} \\
1726 \mathrm{~m}\end{array}$ & $\begin{array}{l}\text { Wind speed, air temperature and humidity }(2 \text { and } 10 \mathrm{~m}) \text {, wind direction, air pressure, } \\
\text { precipitation, four components of radiation, and LST. Soil: temperature and moisture } \\
\text { profile }(5,10,20,40,80 \text {, and } 160 \mathrm{~cm}) \text { and heat flux }(5 \text { and } 15 \mathrm{~cm}) .\end{array}$ & Desert steppe \\
\hline Guantan & $\begin{array}{l}100^{\circ} 15^{\prime} \mathrm{E} \\
38^{\circ} 32^{\prime} \mathrm{N} \\
2835 \mathrm{~m}\end{array}$ & $\begin{array}{l}\text { Wind speed, air temperature and humidity }(2,10 \text {, and } 24 \mathrm{~m}) \text {, four components of radiation } \\
(1.68 \text { and } 19.75 \mathrm{~m}) \text {, wind direction, air pressure, precipitation, snow depth, and PAR. Soil: } \\
\text { temperature and moisture profile }(5,10,20,40,80 \text {, and } 120 \mathrm{~cm}) \text {, frost depth, and heat flux } \\
(5 \text { and } 15 \mathrm{~cm}) . \mathrm{EC} \text {, sap flow (Eq. } 3) \text {, fall-through, stemflow. }\end{array}$ & Forest \\
\hline Maliantan & $\begin{array}{l}100^{\circ} 18^{\prime} \mathrm{E} \\
38^{\circ} 33^{\prime} \mathrm{N} \\
2817 \mathrm{~m}\end{array}$ & $\begin{array}{l}\text { Wind speed, air temperature and humidity }(2 \text { and } 10 \mathrm{~m}) \text {, wind direction, air pressure, } \\
\text { precipitation, and four components of radiation. Soil: temperature and moisture profile } \\
(5,10,20,40,80 \text {, and } 120 \mathrm{~cm}) \text { and heat flux }(5 \text { and } 15 \mathrm{~cm}) \text {. }\end{array}$ & Grassland \\
\hline A'rou & $\begin{array}{l}100^{\circ} 27^{\prime} \mathrm{E} \\
38^{\circ} 03^{\prime} \mathrm{N} \\
3033 \mathrm{~m}\end{array}$ & $\begin{array}{l}\text { Wind speed, air temperature and humidity }(2 \text { and } 10 \mathrm{~m}) \text {, wind direction, air pressure, } \\
\text { precipitation, and four components of radiation. Soil: temperature, moisture, water } \\
\text { potential profile }(10,20,40,80,120 \text {, and } 160 \mathrm{~cm}) \text {, and heat flux }(5 \text { and } 15 \mathrm{~cm}) . \mathrm{EC}(3.15 \mathrm{~m}) \text {. }\end{array}$ & Alpine meadow \\
\hline Binggou & $\begin{array}{l}100^{\circ} 13^{\prime} \mathrm{E} \\
38^{\circ} 04^{\prime} \mathrm{N} \\
3407 \mathrm{~m}\end{array}$ & $\begin{array}{l}\text { Wind speed, air temperature and humidity }(2 \text { and } 10 \mathrm{~m}) \text {, wind direction, air pressure, } \\
\text { precipitation, and four components of radiation. Soil: temperature and moisture profile } \\
(5,10,20,40,80 \text {, and } 120 \mathrm{~cm}) \text { and heat flux }(5 \text { and } 15 \mathrm{~cm}) \text {. }\end{array}$ & Alpine marshy meadow \\
\hline Yakou & $\begin{array}{l}100^{\circ} 14^{\prime} \mathrm{E} \\
38^{\circ} 01^{\prime} \mathrm{N} \\
4101 \mathrm{~m}\end{array}$ & $\begin{array}{l}\text { Wind speed, air temperature and humidity }(2 \text { and } 10 \mathrm{~m}) \text {, wind direction, air pressure, } \\
\text { precipitation, snow depth, and four components of radiation. Soil: temperature and } \\
\text { moisture profile }(5,10,20,40,80 \text {, and } 120 \mathrm{~cm}) \text { and heat flux }(5 \text { and } 15 \mathrm{~cm}) .\end{array}$ & Cold desert \\
\hline
\end{tabular}

Note: EC is Eddy Covariance system.

Remote-sensing data provided by satellites make it possible to obtain consistent and frequent observations of the spectral albedo and the emittance of radiation from elements in a patchy landscape and on a global scale (Sellers et al., 1990). Land surface variables, such as surface temperature, surface hemispherical albedo, Normalized Difference Vegetation Index (NDVI) and surface thermal emissivity can be derived directly from satellite observations (e.g., Susskind et al., 1984; Che'din et al., 1985; Tucker, 1986; Wan and Dozier, 1989; Menenti et al., 1989; Becker and Li, 1990, 1995; Watson et al., 1990; Baret and Guyot, 1997; Price, 1992; Kahle and Alley, 1992; Li and Becker, 1993; Qi et al., 1994; Schmugge et al., 1995; Sobrino and Raissouni, 2000; Li et al., 2000, 2003; Jia et al., 2003b; Menenti et al., 2001). The regional heat flux can be obtained indirectly using the derived parameters and variables (Pinker, 1990).

In recent years, numerous studies have explored a variety of approaches for estimating the regional distribution of surface heat fluxes (e.g., Kustas et al., 1989; Kustas, 1990; Wang et al., 1995; Menenti et al., 1991; Menenti and Choudhury, 1993; Bastiaanssen, 1995a; Su, 2002; Jia et al., 2003b). These methods require specification of the vertical temperature difference between the surface temperature and the air temperature and an exchange resistance. More recent, NOAA/AVHRR (the National Oceanic and Atmospheric Administration/Advanced Very High Resolution Radiometer), GMS (Geostationary Meteorological Satellite) and Landsat-7 ETM (Enhanced Thematic Mapper) data were used to determine regional land surface heat fluxes over the heterogeneous landscape of the Tibetan Plateau (Ma et al., 2003a,b, 2009; Ma, 2007; Ma and Ma, 2006; Oku et al., 2007). However, most remote-sensing retrieval methods have been applied in homogeneous moist or semiarid regions, and investigations in the heterogeneous landscape of arid and cold regions (e.g., WATER area) using higherresolution satellite data (on the order of $10 \sim 100 \mathrm{~m}$ ) are rare or limited.

\section{Study area and data}

\subsection{Study area}

WATER is a multiscale land surface/hydrological experiment in a cold and arid region. In this paper, Yingke, Huazhaizi, Guantan, Maliantan, A'rou, Binggou and Yakou are selected as weather stations to represent the middle and upper streams of the Heihe River Basin. Yingke station, located to the south of the city of Zhangye, is a typical irrigated farmland. The primary crops are corn and wheat. Huazhaizi station 


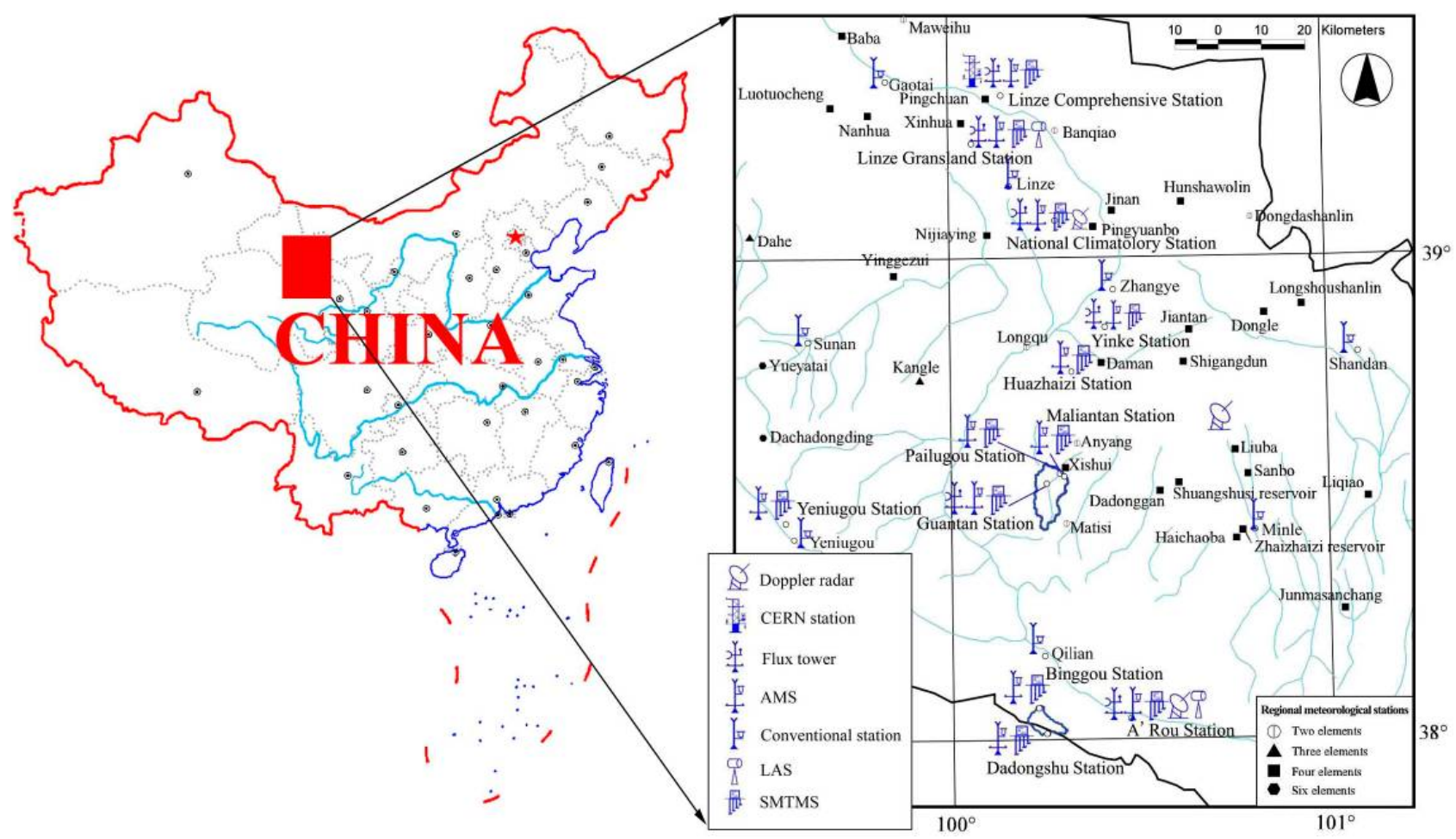

Fig. 1. Map of studying area and observation sites during the WATER.

is located on desert steppe to the south of Zhangye oasis. Guantan is a forest station in the southern part of Zhangye oasis. Maliantan is a grassland station near Guantan station. A'rou station is located in the middle reaches of the Babao River Basin. The seasonally frozen soil is widely distributed. Binggou station is a high-mountain drainage system, and the mean depth of the seasonal snowpack is approximately 0.5 $\mathrm{m}$, with a maximum of $0.8-1.0 \mathrm{~m}$. Yakou station is located on a mountain pass. To ensure the consistency of the observation results at these stations, all instruments were demarcated before the experiments. Further details are given in Table 1 and Fig. 1 (Li et al., 2009).

\subsection{Ground measurements and preprocessing}

Most of the relevant data, obtained at the WATER (Fig. 1) stations to support the parameterization of land surface heat fluxes and the analysis of ASTER images in this paper, consist of surface radiation budget components, surface radiometric temperature, surface albedo, humidity, wind speed and direction measured by the Atmospheric Boundary Layer (ABL) towers and Automatic Weather Stations (AWSs), turbulent fluxes measured by the eddy correlation technique, soil heat flux, soil temperature profiles, soil moisture profiles, and the vegetation state.
The land surface data observed at two of the WATER stations (Guantan and Yingke) were collected on a mountain pass from an EC (Eddy Covariance) system, from which sensible and latent heat fluxes were estimated. The turbulence data, observed with a sonic anemometer-thermometer and an infrared hygrometer, were processed using the eddy correlation methodology. Improved EdiRe (a software tool for micrometeorological applications developed at the University of Edinburgh) processing, including removal of outliers, coordinate rotation, virtual temperature correction, time delay removal, frequency response correction, WPL correction and stability testing, was implemented to average time series datasets of sensible and latent heat flux into 30-min time periods.

\subsection{Satellite data}

ASTER covers a wide spectral region and uses 14 bands from the visible to the thermal infrared with high spatial, spectral and radiometric resolution. The spatial resolution varies with wavelength: $15 \mathrm{~m}$ in the visible and near-infrared bands (VNIR, $0.52-0.86 \mu \mathrm{m}$ ), $30 \mathrm{~m}$ in the shortwave infrared bands (SWIR, 1.6-2.43 $\mu \mathrm{m}$ ), and $90 \mathrm{~m}$ in the thermal infrared bands (TIR, 8.1-11.6 $\mu \mathrm{m}$ ) (Yamaguchi, 1998). The level of ASTER data is L1B. In this paper, four scenes of ASTER data over the mid- to upstream sections of the Heihe River Basin were used (https://wist.echo.nasa.gov/). The ASTER 


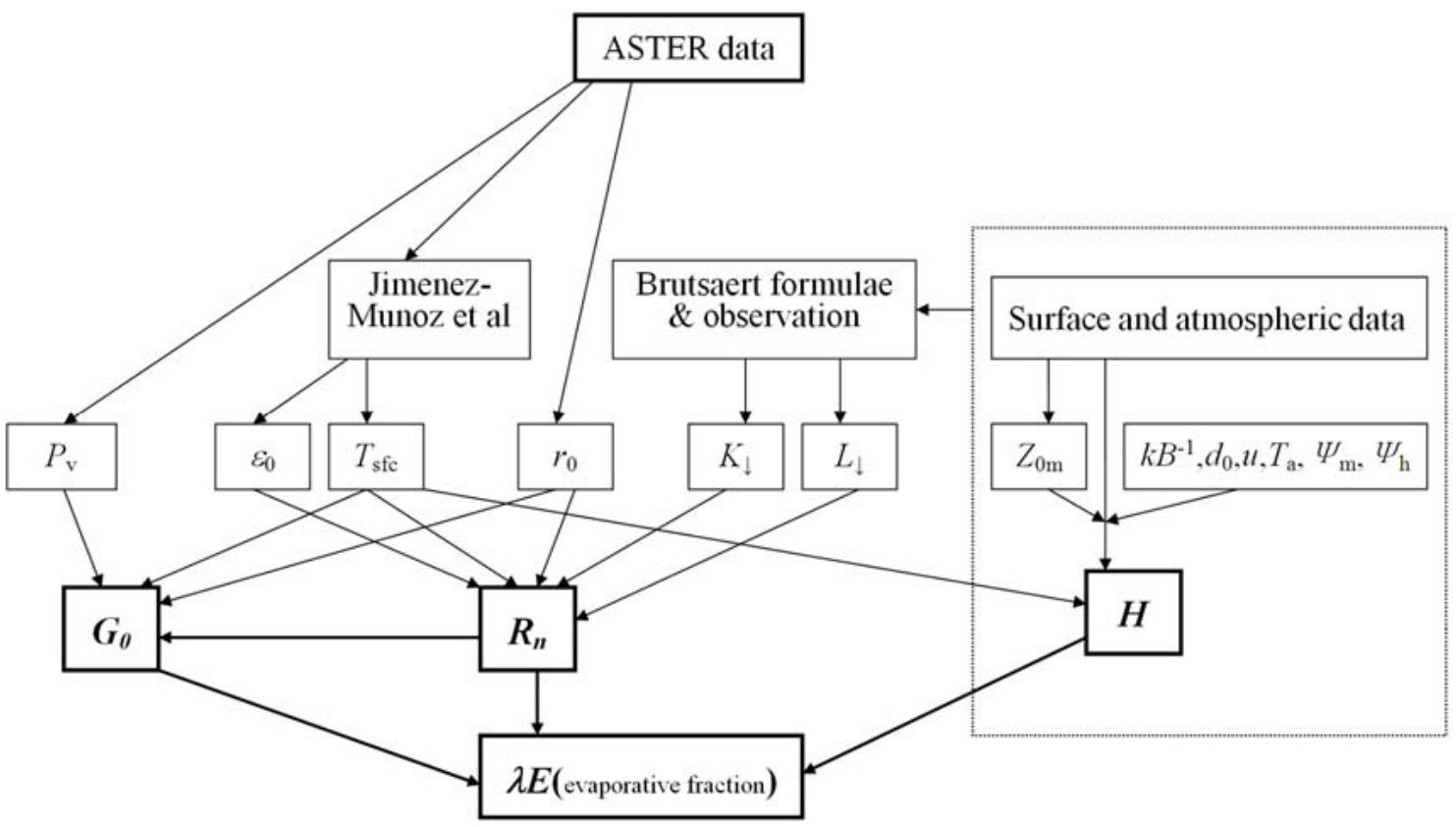

Fig. 2. Diagram of parameterization procedure by combining ASTER data with field observations. $\left(P_{\mathrm{v}}\right.$ is vegetation coverage and $k B^{-1}$ is the parameterization for excess resistance for heat transportation.)

observation times were 12:19, 3 May and 4 June 2008, Beijing time $(\mathrm{GMT}+8)$.

\section{Methodology}

\subsection{SEBS algorithm}

The Surface Energy Balance System (SEBS; Su, 2002) was proposed to estimate atmospheric turbulent fluxes and the evaporative fraction using satellite earth observation data in combination with meteorological information.

The surface energy balance is commonly written as

$$
R_{\mathrm{n}}=G_{0}+H+\lambda E
$$

where $R_{\mathrm{n}}$ is the net radiation $\left(\mathrm{W} \mathrm{m}^{-2}\right), G_{0}$ is the soil surface heat flux $\left(\mathrm{W} \mathrm{m}^{-2}\right), H$ is the turbulent sensible heat flux $\left(\mathrm{W} \mathrm{m}^{-2}\right)$ and $\lambda E$ is the turbulent latent heat flux $\left(\mathrm{W} \mathrm{m}^{-2}\right)$.

SEBS consists of a set of tools for determining the land surface physical parameters, such as albedo, emissivity, temperature, and vegetation coverage, from spectral reflectance and radiance measurements. In addition, SEBS contains a model for determining the roughness length for heat transfer (Su et al., 2001; Jia et al., 2003b). Parameterization methodology applicable to this study is presented, and the retrieval of the components of land surface parameters is discussed further in Sect. 3.2.

In this study, the SEBS retrieval algorithm is applied to the ASTER data to evaluate the applicability of this approach to an arid and cold environment. First, the ASTER data from the 3 ASTER instrument subsystems (VNIR, SWIR and TIR) were reprojected to produce the same spatial resolution. The general concept of this methodology is shown in Fig. 2. NDVI was derived from bands 2 and 3 of the ASTER data. The surface albedo for shortwave radiation $\left(r_{0}\right)$ was retrieved from the narrowband-broadband conversion in Liang (2001). The land surface temperature (LST) $\left(T_{\text {sfc }}\right)$ was derived using a method developed by Jimenez-Munoz and Sobrino (2006) from multispectral thermal infrared data. Jimenez-Munoz and Sobrino (2006) also evaluated a technique to extract emissivity information from multispectral thermal infrared data by adding vegetation information. The radiative transfer model SMAC (Rahman and Dedieu, 1994) was used for atmospheric correction of the VNIR data. The input downward shortwave radiation was retrieved directly from observation data recorded by the WATER AWSs. The surface net radiation flux $\left(R_{\mathrm{n}}\right)$ can be determined by combining the retrieved albedo, the surface emissivity and the LST $\left(T_{\mathrm{sfc}}\right)$ from the ASTER data and the downward short- and longwave thermal radiation from in situ measurements at the AWS stations. On the basis of the field observations, the soil heat flux $\left(G_{0}\right)$ was estimated from the net radiation flux $\left(R_{\mathrm{n}}\right)$ (Eq. 2). The sensible heat flux $(H)$ was estimated from the LST $\left(T_{\text {sfc }}\right)$, the air temperature $\left(T_{\mathrm{a}}\right)$ and other parameters. The regional latent heat flux $(\lambda E)$ was derived using the evaporative fraction, as described in $\mathrm{Su}$ (2002). 
The net radiation flux $R_{\mathrm{n}}$ was estimated as

$$
\begin{aligned}
R_{\mathrm{n}}(x, y) & =K_{\downarrow}(x, y)-K_{\uparrow}(x, y)+L_{\downarrow}(x, y) \\
& -L_{\uparrow}(x, y)=\left\{1-r_{0}(x, y)\right\} \cdot K_{\downarrow}(x, y) \\
& +\varepsilon_{0}(x, y)\left\{L_{\downarrow}(x, y)-\sigma T_{\mathrm{sfc}}^{4}(x, y)\right\}
\end{aligned}
$$

where $\varepsilon_{0}(x, y)$ is the surface emissivity, $K_{\downarrow}\left(\mathrm{W} \mathrm{m}^{-2}\right)$ represents the downward shortwave components $(0.3-3 \mu \mathrm{m})$, and $L_{\downarrow}\left(\mathrm{W} \mathrm{m}^{-2}\right)$ represents the downward longwave $(3-100 \mu \mathrm{m})$ radiation components. The surface albedo $r_{0}(x, y)$ was derived using the narrowband-broadband conversion method in Liang (2001). Because ASTER has nine bands, the conversion from narrowband to broadband albedo can be achieved effectively (Liang, 2001). Liang (2001) found that the conversions were quite linear.

The equation to calculate soil heat flux is given as follows (Su, 2002):

$G_{0}=R_{\mathrm{n}}\left[\Gamma_{\mathrm{c}}+\left(1-f_{\mathrm{c}}\right) \cdot\left(\Gamma_{\mathrm{s}}-\Gamma_{\mathrm{c}}\right)\right]$

where the constants $\Gamma_{\mathrm{c}}=0.05$ for a full vegetation canopy and $\Gamma_{\mathrm{S}}=0.315$ for bare soil (see $\mathrm{Su}, 2002$, for more details). A linear interpolation was performed between these limiting cases using the fractional canopy coverage, $f_{\mathrm{c}}$. In this study, these constants for full canopy and bare soil conditions were evaluated for the Heihe River.

To derive the sensible and latent heat flux, similarity theory was used. In the Atmospheric Surface Layer (ASL), the similarity relationships for the profiles of the mean wind speed, $u$, and the mean potential temperature difference between the surface and the air, $\theta_{0}-\theta_{\mathrm{a}}$, are usually written in integral form as follows:

$$
\begin{gathered}
u=\frac{u_{*}}{k}\left[\ln \left(\frac{z-d_{0}}{z_{\mathrm{om}}}\right)-\Psi_{\mathrm{m}}\left(\frac{z-d_{0}}{L}\right)+\Psi_{\mathrm{m}}\left(\frac{z_{0 \mathrm{~m}}}{L}\right)\right] \\
\theta_{0}-\theta_{\mathrm{a}}=\frac{H}{k u_{*} \rho C_{\mathrm{p}}}\left[\ln \left(\frac{z-d_{0}}{z_{\mathrm{oh}}}\right)-\Psi_{\mathrm{h}}\left(\frac{z-d_{0}}{L}\right)\right. \\
\left.+\Psi_{\mathrm{h}}\left(\frac{z_{0 \mathrm{~h}}}{L}\right)\right]
\end{gathered}
$$

where $z$ is the height above the surface, $u_{*}$ is the friction velocity, $C_{\mathrm{p}}$ is the specific heat of air at constant pressure, $\rho$ is the density of air, $k=0.4$ is von Karman's constant, $d_{0}$ is the zero plane displacement height, $z_{0 \mathrm{~m}}$ is the roughness height for momentum transfer, $\theta_{0}$ is the potential temperature at the surface, $\theta_{\mathrm{a}}$ is the potential air temperature at height $z$, $z_{0 \mathrm{~h}}$ is the scalar roughness height for heat transfer, $\psi_{\mathrm{m}}$ and $\psi_{\mathrm{h}}$ are the stability correction functions for momentum and sensible heat transfer, and $L$ is the Obukhov length. $L$ is defined as follows:

$L=\frac{\rho C_{\mathrm{p}} u_{*}^{3} \theta_{\mathrm{v}}}{k g H}$ where $g$ is the acceleration due to gravity and $\theta_{\mathrm{v}}$ is the virtual potential temperature near the surface. Other parameters can be found in Su (2002). By combining Eqs. (4-6) using an iterative method, we can estimate the sensible heat flux.

To estimate the evaporative fraction (see below), SEBS makes use of the energy balance at the limiting cases of the dry limit and the wet limit, such that the relative evaporation (ratio of the actual evaporation to the evaporation at the wet limit) can be derived as

$\Lambda_{\mathrm{r}}=1-\frac{H-H_{\mathrm{wet}}}{H_{\text {dry }}-H_{\mathrm{wet}}}$

where $H_{\text {wet }}$ is sensible heat flux at the wet limit and $H_{\text {dry }}$ sensible heat flux at the dry limit. The estimation of $H_{\text {wet }}$ and $H_{\text {dry }}$ is detailed in $\mathrm{Su}$ (2002). The evaporative fraction (ratio of latent heat flux to available energy) was estimated by the following equation:

$\Lambda=\frac{\lambda E}{R_{\mathrm{n}}-G}=\frac{\Lambda_{\mathrm{r}} \cdot \lambda E_{\mathrm{wet}}}{R_{\mathrm{n}}-G}$

where $\lambda E_{\text {wet }}$ is the latent heat flux at the wet limit (i.e., evaporation is only limited by the available energy under the given surface and atmospheric conditions). The latent heat flux $(\lambda E)$ can then be calculated by

$\lambda E=\Lambda\left(R_{\mathrm{n}}-G_{0}\right)$.

\subsection{Determination of parameters}

Land surface parameters play an important role in the airland interaction over the study area. Study of this interaction requires an understanding of land surface parameters in time and space at various scales. Because a satellite is able to observe the global surface continuously from space, it can be used to monitor land surface parameters. The most common (and useful) land surface parameters include the surface albedo, the NDVI, the vegetation coverage $P_{\mathrm{v}}$ (or fractional vegetation cover $f_{\mathrm{c}}$ ), and the land surface temperature. These parameters are required for the application of SEBS at the regional scale.

\subsubsection{Surface albedo}

The surface albedo $r_{0}(x, y)$ was derived using the previously mentioned narrowband-broadband conversion method given by Liang (2001). The resultant linear equations were collated as follows:

$$
\begin{aligned}
r_{0}= & 0.484 \alpha_{1}+0.335 \alpha_{3}-0.324 \alpha_{5}+0.551 \alpha_{6} \\
& +0.305 \alpha_{8}-0.367 \alpha_{9}-0.0015
\end{aligned}
$$

where $i(i=1-9)$ indexes the corresponding ASTER band surface reflectance values. 

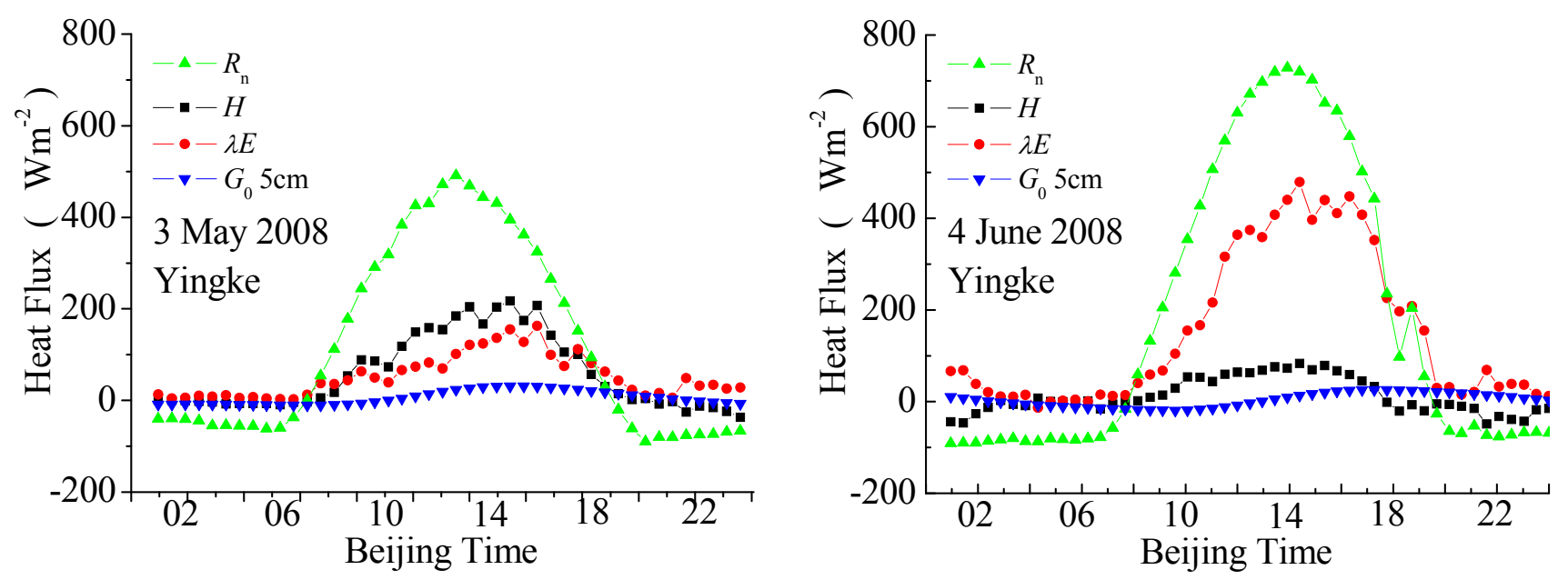

Fig. 3. Diurnal variations of land surface heat fluxes over the WATER area. Note: the soil heat flux is measurements at $5 \mathrm{~cm}$ below the land surface.

\subsubsection{NDVI}

Because chlorophyll exhibits strong spectral absorption in the visible region (Tucker, 1986), land surface spectral reflectance provides information on the presence of chlorophyll and thus on surface vegetation conditions. This information can be utilized to calculate the NDVI for each pixel from the reflectances in the red and infrared channels. For the ASTER data, the NDVI is given as follows:

$\operatorname{NDVI}(x, y)=\frac{\text { band } 3-\text { band } 2}{\text { band } 3+\text { band } 2}$

where band 3 is the ASTER reflectance in the near-infrared red channel and band 2 is the ASTER reflectance in the red channel.

\subsubsection{Vegetation coverage $\boldsymbol{P}_{\mathrm{v}}$}

The vegetation coverage $\left(P_{\mathrm{v}}\right)$ is a useful indicator for monitoring the condition of the soil surface and the health of grassland and can be derived as follows:

$P_{\mathrm{v}}(x, y)=\left[\frac{\mathrm{NDVI}(x, y)-\mathrm{NDVI}_{\min }}{\mathrm{NDVI}_{\text {max }}-\mathrm{NDVI}_{\text {min }}}\right]^{2}$

where $\mathrm{NDVI}_{\text {min }}$ and $\mathrm{NDVI}_{\text {max }}$ are the NDVI values for bare soil and full vegetation, respectively (Carlson and Ripley, 1997).

\subsubsection{Land surface temperature}

The land surface temperature was derived from multispectral thermal infrared data using a method developed by JimenezMunoz and Sobrino (2006). The main processes involved are based on the Temperature/Emissivity Separation (TES) method (Gillespie et al., 1998) and can be simplified by using two different TIR channels: $i$ and $j$.

$T_{\mathrm{sfc}}=T_{i}+a_{1}\left(T_{i}-T_{j}\right)+a_{2}\left(T_{i}-T_{j}\right)^{2}+a_{0}$

using coefficients obtained from simulated data by JimenezMunozet and Sobrino (2006).

\subsubsection{Surface roughness parameters}

Several physically based models are currently used to estimate $z_{0 \mathrm{~m}}$ and $z_{0 \mathrm{~h}}$. In general, the models account for canopy structure and the height of vegetation for given land-use types (Raupach, 1992, 1994; Massman, 1999; Hasager and Jensen, 1999). As a simplification of these models, an empirical relationship between $z_{0 \mathrm{~m}}$ and NDVI was used by Bastiaanssen (1995b) to determine the regional $z_{0 \mathrm{~m}}$ as follows:

$z_{0 \mathrm{~m}}=\exp \left(C_{1}+C_{2} \cdot \mathrm{NDVI}\right)$

where $C_{1}$ and $C_{2}$ are empirical coefficients that are dependent on the experimental area. According to Bastiaanssen (1995b), $C_{1}=-5.5$ and $C_{2}=5.8$ were assumed and evaluated for the study area. Jia et al. (2003a) have evaluated the constants $C_{1}$ and $C_{2}$ and concluded that for the Heihe area, different values need to be used (see discussions for more details).

Su et al. (2001) developed a physical model for the roughness length for heat transfer. In their model, the $z_{0 \mathrm{~h}}$ in terms of $k B^{-1}\left(k B^{-1}=\ln \left(z_{0 \mathrm{~m}} / z_{0 \mathrm{~h}}\right)\right)$ is expressed as a function of the surface condition and the aerodynamic variables and is used in SEBS in a modified form by Su (2002). 

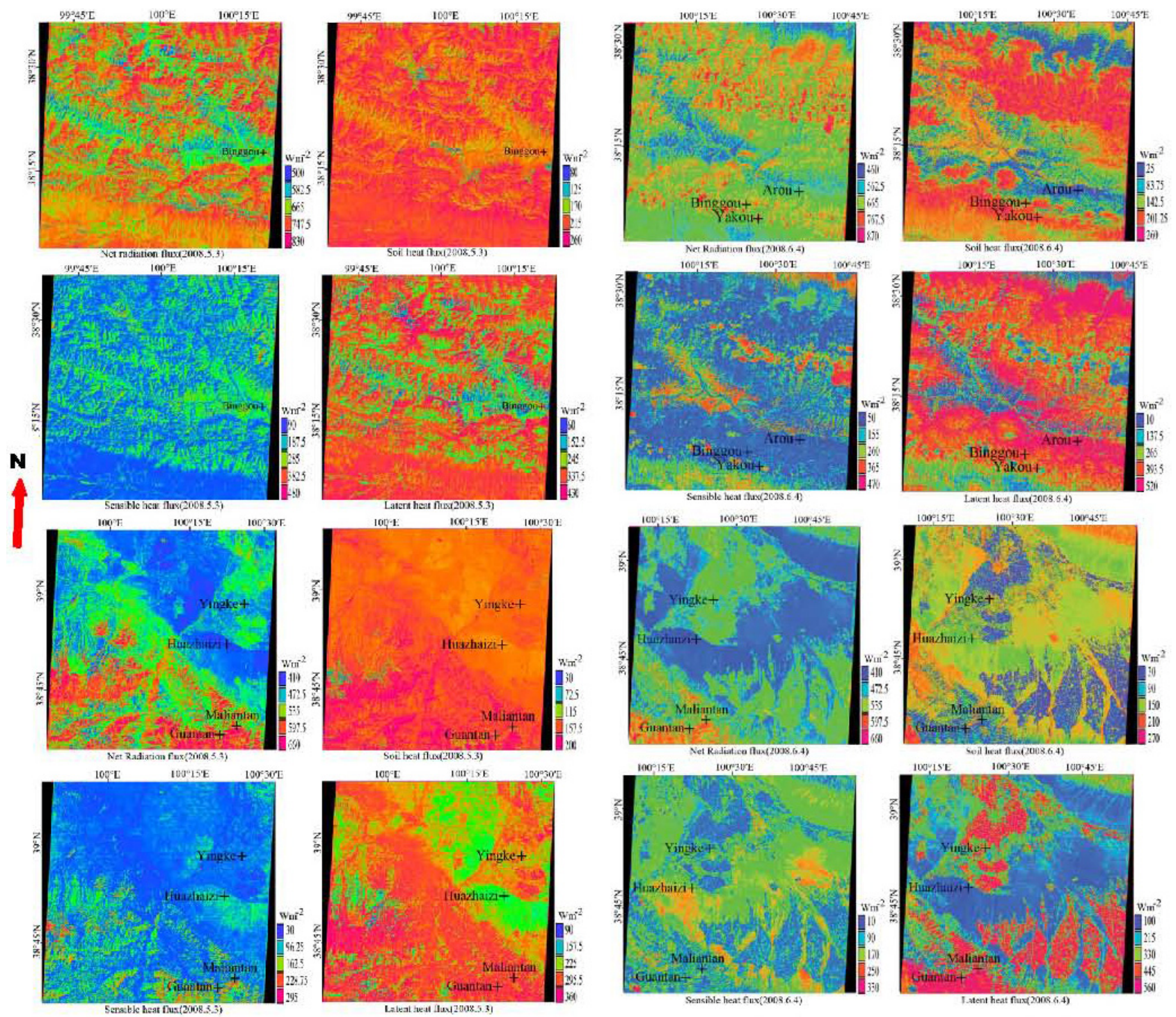

Fig. 4. Distribution maps of land surface heat fluxes over the WATER area.

\section{Results and discussion}

\subsection{Characteristics for land surface heat fluxes from ground measurements}

Figure 3 shows the Yingke and Guantan stations' diurnal variations in surface heat fluxes within the study area, including the net radiation $\left(R_{\mathrm{n}}\right)$, the sensible heat flux $(H)$, the latent heat flux $(\lambda E)$ and the soil heat flux $\left(G_{0}\right)$ at $5 \mathrm{~cm}$ below the land surface (observational values used directly). As the net radiometer at the Guantan station was located within a forest, the data obtained by this instrument are not comparable to satellite observations and are therefore omitted from the subsequent comparisons. We can state our findings as follows:
1. Yingke station: the sensible heat flux was largest in May, whereas in June, the latent heat flux represented the largest component of the surface energy budget. At this time, plant water demand was highest because of transpiration. This observed maximum occurred because high corn was beginning to flower and because irrigation was in use. At the same time, the area presented good surface crop coverage. These results are consistent with the remote-sensing results (cf. Figs. 4 and 5). The soil heat flux was directly measured at $5 \mathrm{~cm}$ below the land surface. Before planting and sprouting during the crop season, the soil heat flux was relatively large. As the crop matured, the soil heat flux decreased significantly. The soil heat flux $5 \mathrm{~cm}$ below the surface 

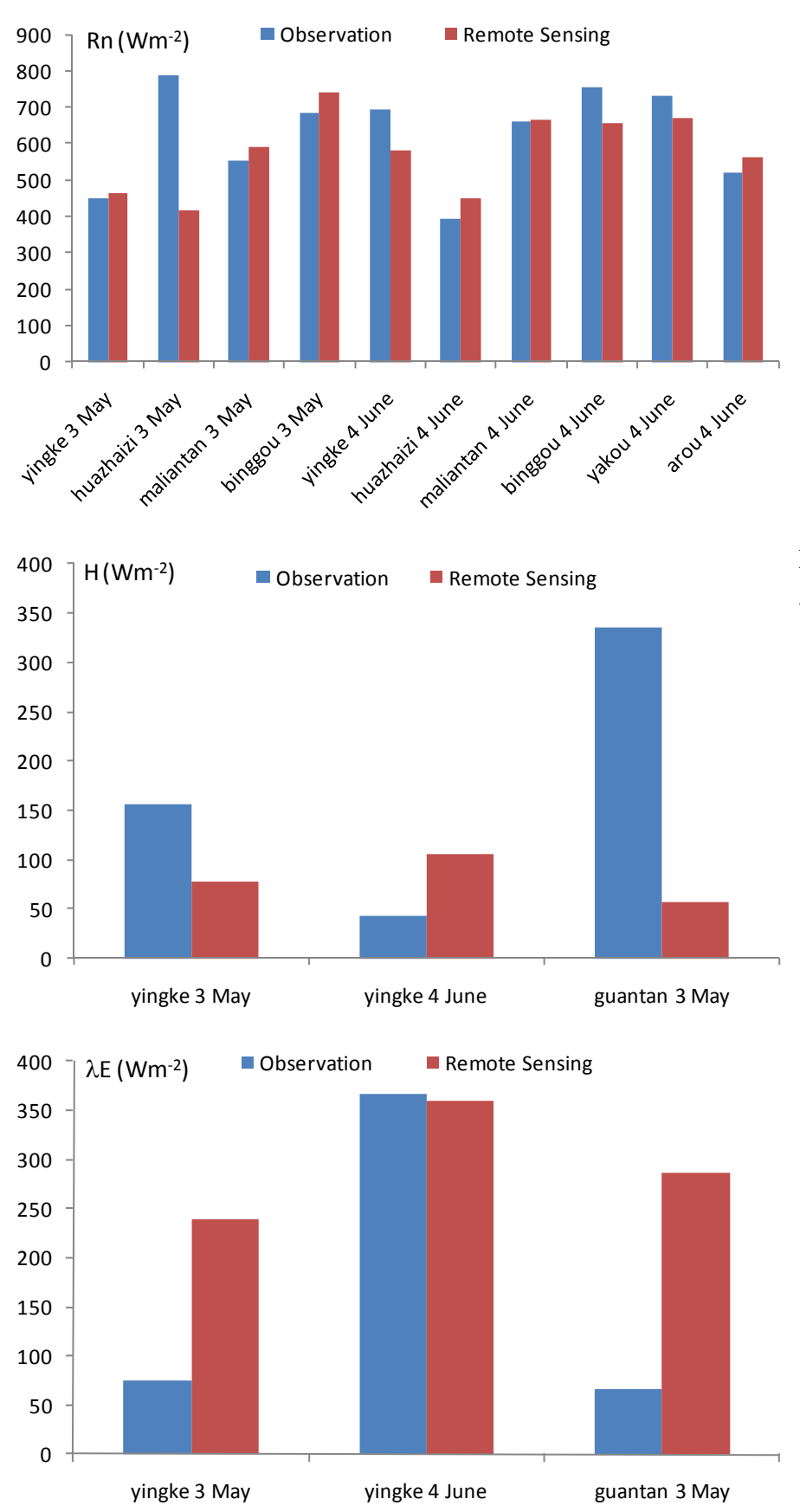

Fig. 5. Validation of the derived net radiation $R_{\mathrm{n}}$, sensible heat flux $H$ and latent heat flux $\lambda E$ against ground measurements over the WATER stations, Yingke, Huazhaizi, Guantan, Maliantan, Arou, Binggou and Yakou. Note: The sites with missing observation data were not listed in the figures.

was calculated to the land surface (Ma and Ma, 2006) and compared with satellite retrievals.

2. Guantan station: as in any forest, the height of the canopy was not very consistent, and the measurements cannot directly represent land-surface processes.

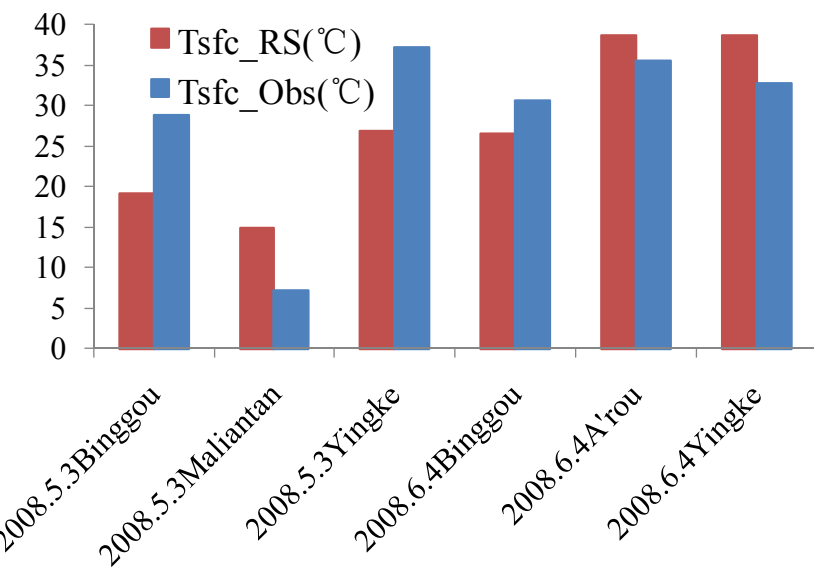

Fig. 6. Validation of the derived land surface temperature against ground measurements over the WATER stations.

Estimates of both the sensible and latent heat fluxes are therefore difficult to obtain. As a result, the remotesensing estimates of sensible and latent heat fluxes in this particular environment are unreliable. For this reason, we did not compare remote sensing and surface observations at Guantan station. The results were compared only at the other sites.

3. To validate the remote-sensing results, the land surface albedo and the surface temperature were calculated using observational data (Binggou, Maliantan, Yingke and Huazhaizi). Using the existing observational data (portions of the data for these sites are missing) and calculating the albedo and LST from satellite data on 3 May and 4 June 2008, we can see that the results of remote sensing and ground observations can be acceptable for calculating land surface heat fluxes. This finding indicates that our land surface parameterization scheme is feasible (cf. Figs. 6 and 7). Here, the APD (absolute percent difference) was calculated between the derived value ( $\left.H_{\text {derived }}\right)$ and measured value $\left(H_{\text {measured }}\right)$ at a point as $\mathrm{APD}=\frac{\left|H_{\text {derived }}-H_{\text {measured }}\right|}{H_{\text {measured }}}$. For our analyses, the APD for the LST was less than $3 \%$ and surface albedo was less than $20 \%$. The RMSE (root mean square error) for LST was $19^{\circ}$ and the surface albedo was 0.1 . For regional land surface heat flux analysis, it is a way to evaluation the parameterization if it can be used in Northwest China, especially in oasis or gobi desert.

\subsection{Heat flux estimation using SEBS}

Figure 4 shows the distribution maps of the surface heat fluxes for the study area. Figure 5 shows the validation results for the derived net radiation, the sensible heat flux and the latent heat flux compared with ground measurements at the WATER stations (Yingke, Huazhaizi, Guantan, Maliantan, A'rou, Binggou and Yakou). The ground AWS 


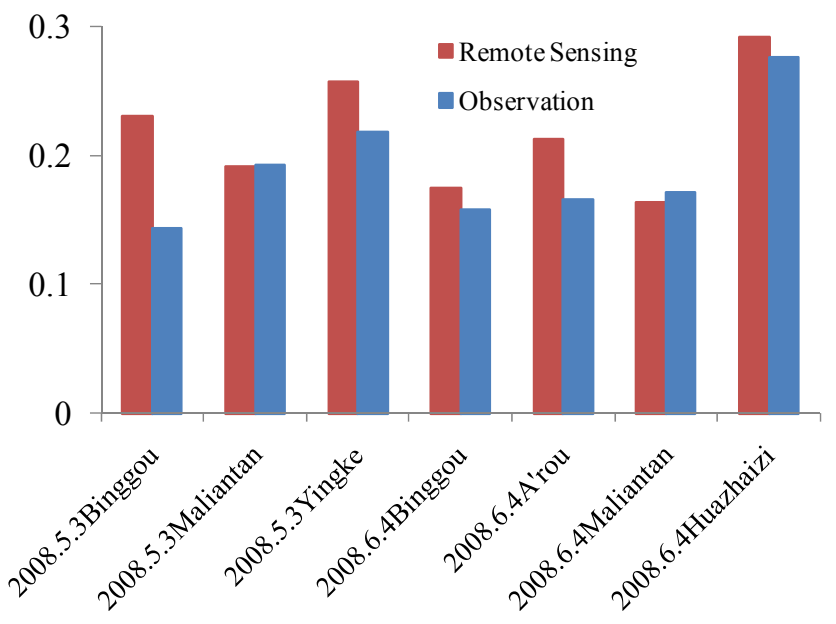

Fig. 7. Validation of the derived albedo against ground measurements over the WATER stations.

measurements were averaged over a 10 -min period, and the EC was 30 min.

The results showed the following:

1. The derived net radiation flux over the study area was very close to the field measurements. The changes in the net radiation were comparable to the changes in the surface temperature, the albedo and the downward shortwave radiation. Here, the surface temperature, the albedo and the downward shortwave radiation matched the measured data well. The net radiation flux was also in reasonably nice agreement with the ground-based observations, with an RMSE value of $41.5 \mathrm{~W} \mathrm{~m}^{-2}$ (Fig. 5). But a error accruing of net radiation flux at Huazhaizi site, as we know Huazhaizi site located nearby the Zhangye Osis then the advection of osis and gobi desert were very huge. The boundary layer energy distribution was disarranged especially at noon. All of these reflect on the net radiation flux error between remote sensing and land surface observation.

2. Overall, the satellite remote-sensing results within a credible range for sensible heat flux in the study area are not as well as the results for the net radiation flux presented above. The parameterization scheme for sensible heat flux is the most complex in the entire land surface energy budget, especially for Guantan station. The station was located in the forest (as described above in reference to the table). Many uncertain factors may have produced some deviations from credible values. The resulting calculations can thus produce a large difference between the remote-sensing results and observations at the station.

3. The latent heat flux is obtained by calculations involving the evaporative fraction, and these calculations are the essence of SEBS. It can be seen from the figure that the calculated latent heat flux is acceptable for the Yingke irrigation area at limited case, especially in June. June is the season of irrigation, and crop growth is substantial. The figure shows that the satellite retrieval results and the observations are similar on 4 June. The latent heat flux reaches $350 \mathrm{~W} \mathrm{~m}^{-2}$ during this season. This value results from the fact that the Yingke irrigation area is largely occupied by irrigated corn. With the addition of field irrigation, the land surface is very moist. All of these factors lead to a large surface latent heat flux. This result also shows that the evapotranspiration (ET) is worked out as well. The values derived from the remote-sensing results were too large at the Guantan site because the large areas of forest (described earlier) in the area in which the land surface observations were made led to considerable difficulties. On the contrary it is a bad latent heat flux results on 3 May at Yingke and Guantan site, the observation latent heat flux looks so small but the results from SEBS looks realistic. So we think two reasons to illustration the bad results: first is the unhappy land surface observation for latent heat flux and the second is the SEBS cannot suit the complicated condition. Overall, however, SEBS, can be used to estimate the heterogeneous land surface latent heat flux distribution under limited condition.

\section{Concluding remarks}

In this study, the regional distributions of land surface heat fluxes over middle and upper streams of the Heihe River Basin were derived with the aid of ASTER data and field observations. The region characterized by partial vegetation cover provided more accurate estimates (e.g., Yingke station, 4 June), compared with areas where the land cover consists of bare soil or densely vegetated areas such as forests, where the results were poor (e.g., Guantan station).

On the basis of this particular study, SEBS can be used to estimate turbulent heat fluxes with acceptable accuracy in areas where there is partial vegetation cover. For example, for 4 June at Yingke station, the remotely sensed estimates of the sensible heat flux value were large and the corresponding latent heat flux value was small. It is very important to perform calculations using ground-based observational data for parameterization in SEBS in the future.

Nevertheless, the remote-sensing results (estimated from an average $3 \times 3$ pixel matrix) can provide improved explanations of land surface fluxes over varying land coverage at greater spatial scales.

Acknowledgements. This work was under the CAS Action Plan for West Development Program (KZCX2-XB2-09-04), the CAS projects (KZCX2-YW-QN309 and KZCX2-YW-Q10-2), Chinese State Key Basic Research Project (2010CB951701, 2005CB422003 and 2007CB714400). The auspices of the National Natural Science Foundation of China (40905017, 40825015 and 40810059006), 
the Key Projects of International Cooperation, CAS (GJHZ0735) and the EU-FP7 project CEOP-AEGIS (Grant Number: 212921). Special thanks are given to the two reviewers and the Editor Xin Li for very constructive comments especially thanks Li Jia, words and deeds, I will always benefit.

Edited by: X. Li

\section{References}

Baret, F. and Guyot, G.: Potentials and limits of vegetation indices for LAI and APAR assessment, Remote Sens. Environ., 35, 161173, 1997.

Bastiaanssen, W. G. M.: Regionalization of surface fluxes and moisture indicators in composite terrain, $\mathrm{PhD}$ Thesis, Wageningen Agric. Univ., Wageningen, Netherlands, 273 pp., 1995a.

Bastiaanssen, W. G. M.: Regionalization of Surface Flux Densities and Moisture Indicators in Composite Terrain, Ph.D. thesis, Wageningen Agric. Univ., Wageningen, Netherlands, 143-161, 1995b.

Becker, F., and Li, Z.-L.: Surface temperature and emissivity at various scales: Definition, measurement and related problems, Remote Sens. Rev., 12, 225-253, 1995.

Carlson, T. N. and Ripley, D. A.: On the relation between NDVI, fractional vegetation cover, and leaf area index, Remote Sens. Environment, 62, 241-252, 1997.

Che'din, A., Scott, N. A., Wahiche, C., and Moulinier, P.: The improved initialisation inversion method: A high resolution physical method for temperature retrievals from Tiros-N series, J. Clim. Appl. Meteorol., 24, 124-143, 1985.

Gillespie, A. R., Rokugawa, S., Hook, S., Matsunaga, T., and Kahle, A. B.: A temperature and emissivity separation algorithm for Advanced Spaceborne Thermal Emission and Reflection Radiometer (ASTER) images, IEEE T. Geosci. Remote, 36, 1113-1126, 1998.

Hasager, C. B. and Jensen, N. O.: Surface-flux aggregation in heterogeneous terrain, Q. J. Roy. Meteorol. Soc., 125, 2075-2102, 1999.

Jia, L., Li, Z.-L., Menenti, M., Su, Z., Verhoef, W., and Wan, Z.: A practical algorithm to infer soil and foliage component temperatures from bi-angular ATSR-2 data, Int. J. Remote Sens., 24(23), 4739-4760, 2003a.

Jia, L., Su, Z., van den Hurk, C., Massimo, M., Arnold, M., Henk, A., Javier, B., Manuel, I., and Antonio, C.: Estimation of sensible heat flux using the Surface Energy Balance System (SEBS) and ATSR measurements, J. Phys. Chem. Earth, 8, 75-88, 2003 b.

Jimenez-Munoz, J. C. and Sobrino, J. C.: Feasibility of Retrieving Land-Surface Temperature from ASTER TIR bands using twochannel algorithms: A case study of agricultural areas, IEEE T. Geosci. Remote, 4(1), 60-64, 2006.

Kahle, A. B. and Alley, R. E.: Separation of temperature and emittance in remotely sensed radiance measurements, Remote Sens. Environ., 42, 107-112, 1992.

Kustas, W. P.: Estimates of evapotransiration with a one- and twolayer model of heat transfer over partial canopy cover, J. Appl. Meteorol., 29, 704-715, 1990.

Kustas, W. P. and Daughtry, C. S. T.: Estimation of the soil heat flux/net radiation ratio from spectral data, Agr. Forest Meteorol., 39, 205-223, 1990.
Kustas, W. P., Choudhury, B. J., Moran, M. S., Reginato, R. J., Jackson, R. D., Gay, L. W., and Weaver, H. L.: Determination of sensible heat flux over sparse canopy using thermal infrared data, Agr. Forest Meteorol., 44, 197-216, 1989.

Li, X., Li, X. W., Li, Z. Y., Ma, M. G., Wang, J., Xiao, Q., Liu, Q., Che, T., Chen, E. X., Yan, G. J., Hu, Z. Y., Zhang, L. X., Chu, R. Z., Su, P. X., Liu, Q. H., Liu, S. M., Wang, J. D., Niu, Z., Chen, Y., Jin, R., Wang, W. Z., Ran, Y. H., Xin, X. Z., and Ren, H. Z.: Watershed Allied Telemetry Experimental Research, J. Geophys. Res.-Atmos., 114, D22103, doi:10.1029/2008JD011590, 2009.

Li, Z.-L. and Becker, F.: Feasibility of land surface temperature and emissivity determination from AVHRR data, Remote Sens. Environ., 43, 67-85, 1993.

Li, Z.-L., Stoll, M. P., Zhang, R. H., Jia, L., and Su, Z.: On the separate retrieval of soil and vegetation temperatures from ATSR2 data, Sc. China Ser. E, 30, 27-38, 2000.

Li, Z.-L., Jia, L., Su, Z., Wan, Z., Zhang, R. H.: A new approach for retrieving precipitable water from ATSR-2 split window channel data over land area, Int. J. Remote Sens., 24(24), 5095-5117, 2003.

Liang, S.: Narrowband to broadband conversions of land surface albedo I Algorithms, Remote Sens. Environ., 76, 213-238, 2001.

Ma, W. and Ma, Y.: The annual variations on land surface energy in the northern Tibetan Plateau, Environ. Geol., 50(4). 645-650, doi:10.1007/s00254-006-0238-9, 2006.

Ma, Weiqiang, Ma, Yaoming, Li, Maoshan, Hu, Zeyong, Zhong, Lei, Su, Zhongbo, Ishikawa, Hirohiko, and Wang, Jiemin: Estimating surface fluxes over the north Tibetan Plateau area with ASTER imagery, Hydrol. Earth Syst. Sci., 13, 57-67, doi:10.5194/hess-13-57-2009, 2009.

Ma, Y.: Determination of regional surface heat fluxes over heterogeneous landscapes by integrating satellite remote sensing with boundary layer observations, $\mathrm{PhD}$ Thesis, Wageningen University, 2006.

Ma, Y., Su, Z., Koike, T., Yao, T., Ishikawa, H., Ueno, K., and Menenti, M.: On measuring and remote sensing surface energy partitioning over the Tibetan Plateau - From GAME/Tibet to CAMP/Tibet, Phys. Chem. Earth, 28, 63-74, $2003 \mathrm{a}$.

Ma, Y., Ishikawa, H., Tsukamoto, O., Menenti, M., Su, Z., Yao, T., Koike, T., and Yasunari, T.: Regionalization of surface fluxes over heterogeneous landscape of the Tibetan Plateau by using satellite remote sensing, J. Meteorol. Soc. Jpn., 81, 277-293, 2003 b.

Ma, Y., Zhong, L., Su, Z., Ishikawa, H., Menenti, M., and Koike, T.: Determination of regional distributions and seasonal variations of land surface heat fluxes from Landsat7 Ehanced Thematic Mapper data over the central Tibetan Plateau area, Journal of Geophysics Research, 111, D10305, doi:10.1029/2005JD006742, 2006.

Massman, W. J.: A model study of $k B_{\mathrm{B}}^{-1} \mathrm{H}$ for vegetated surfaces using "localized near-field" Lagrangian theory, J. Hydrol., 223 27-43, 1999.

Menenti, M. and Choudhury, B. J.: Parameterization of land surface evaporation by means of location dependent potential evaporation and surface temperature range, in: Exchange Processes at the Land Surface for a Range of Space and Time Scales, edited by: Bolle, H. J., Feddes, R. A., and Kalma, J. D., IAHS Publ., 212, 561-568, 1993. 
Menenti, M., Bastiaanssen, W. G. M., and Van Eick, D.: Determination of hemispheric albedo with Thematic Mapper data, Remote Sens. Environ., 28, 327-337, 1989.

Menenti, M., Bastiaanssen, W. G. M., Hefny, K., and Abd EI Karim, M. H.: Mapping of ground water losses by evaporation in the Western Desert of Egypt, Rep. 43, DLO Winand Staring Cent., Wageningen, The Netherlands, 1-116, 1991.

Menenti, M., Jia, L., Li, Z.-L., Djepa, V., Wang, J., Stoll, M. P., $\mathrm{Su}, \mathrm{Z}$., and Rast, M.: Estimation of soil and vegetation temperatures from directional thermal infrared observations: The HEIFE, SGP'97, IMGRASS experiments, J. Geophys. Res., 106, 1199712010, 2001.

Oku, Y., Ishikawa, H., and Su, Z.: Estimation of Land Surface Energy Fluxes over the Tibetan Plateau using GMS Data, J. Appl. Meteorol. Clim., 46(1), 183-195, 2007.

Pinker, R. T.: Satellites and our understanding of the surface energy balance, Paleogr. Palaeoclim. Palaeoecol., 82, 321-342, 1990.

Price, J. C.: Estimating vegetation amount from visible and near infrared albedo, Remote Sens. Environ., 41, 29-34, 1992.

Qi, J., Chehbouni, A., Huete, A. R., Kerr, Y. H., and Sorooshian, S.: A modified soil adjusted vegetation index, Remote Sens. Environ., 48, 119-126, 1994.

Rahman, H. and Dedieu, G.: SMAC: a simplified method for atmospheric correction of satellite measurements in the solar spectrum, Int. J. Remote Sens., 15, 123-143, 1994.

Raupach, M. R.: Drag and Drag partition on rough surfaces, Bound.-Layer Meteorol., 60, 375-395, 1992.

Raupach, M. R.: Simplified expressions for vegetation roughness length and zero-plane displacement as functions of canopy height and area index, Bound.-Lay. Meteorol., 71, 211-216, 1994.

Schmugge, T. J., Hook, S., and Kahle, A.: TIMS observation of surface emissivity in HAPEX-Sahel, paper presented at International Geoscience and Remote Sensing Symposium, Inst. of Electr. and Electron. Eng., Florence, Italy, July, 1995.

Sellers, P. J., Rasool, S. I., and Bolle, H. J.: A review of satellite data algorithms for studies of the land surface, B. Am. Meteorol. Soc., 71, 1429-1447, 1990.
Sobrino, J. A. and Raissouni, N.: Toward remote sensing methods for land cover dynamic monitoring: application to Morocco, Int. J. Remote Sens., 21(1), 353-366, 2000.

Su, Z.: The Surface Energy Balance System (SEBS) for estimation of turbulent heat fluxes, Hydrol. Earth Syst. Sci., 6, 85-100, doi:10.5194/hess-6-85-2002, 2002.

Su, Z., Schmugge, T., Kustas, W. P., and Massman, W. J.: An evaluation of two models for estimation of the roughness height for heat transfer between the land surface and the atmosphere, J. Appl. Meteorol., 40(10), 1933-1951, 2001.

$\mathrm{Su}, \mathrm{Z}$., Wen, J., and Wagner, W.: Preface "Advances in land surface hydrological processes - field observations, modeling and data assimilation", Hydrol. Earth Syst. Sci., 14, 365-367, doi:10.5194/hess-14-365-2010, 2010.

Susskind, J., Rosenfield, J., Renter, D., and Chahine, M. T.: Remote sensing of weather and climate parameters from HIRS2/MSU on TIROS-N, J. Geophys. Res., 89, 4677-4697.

Tucker, C. J.: Monitoring the grasslands of semi-arid Africa using NOAA AVHRR data, Int. J. Remote Sens., 7-11, 1383-1622, 1986.

Wan, Z. and Dozier, J.: Land surface temperature measurement from space: Physical principles and inverse modelling, IEEE T. Geosci. Remote, 27, 268-278, 1989.

Wang, J., Ma, Y., Menenti, M., Bastiaanssen, W. G. M., and Mistsuta, Y.: The scaling-up of processes in the heterogeneous landscape of HEIFE with the aid of satellite remote sensing, J. Meteorol. Soc. Jpn., 73,1235-1244, 1995.

Watson, K., Kruse, F., and Hummer-Miler, S.: Thermal infrared exploration in the Carlin trend, Geophysics, 55, 70-79, 1990.

Yamaguchi, Y., Kahle, A. B., Tsu, H., Kawakami, T., and Pniel, M.: Overview of the Advanced Spaceborne Thermal Emission and Reflection Radiometer (ASTER), T. Geosci. Remote Sens., 36(3), 1062-1071, 1998. 